\title{
Analysis of the Visual Communication Curriculum Reform under the Background of Quality Education
}

\author{
Du Yan \\ School of Arts, Xi'an University, Xi’an, Shaanxi, China, 710065
}

Keywords: quality education; visual communication; curriculum reform

\begin{abstract}
With the development of economy and society and the adjustment of the goal of talent cultivation, quality education has become the direction of transformation of higher education in China. In the context of quality education, various courses in colleges and universities must be adjusted in time both in the content of education and teaching and in the construction of the curriculum system. The visual communication major is an application-oriented discipline. In recent years, the demand for professional talents in the visual communication has been increasing. Therefore, how to do a good job in visual communication professional teaching reform under the background of quality education is imminent. Based on the requirements of quality education, training excellent professional visual communication professionals is not only a requirement for deepening education reform, but also an internal drive for the development of local economy and the realization of a leap-forward development of colleges and universities.
\end{abstract}

\section{Introduction}

Visual art is an important part of the cultural and creative industries. The visual arts not only covers a wide range of areas, but also covers many fields and plays an important role in upgrading the industrial structure. Visual Communication Professional is a knowledge and technology intensive professional. In recent years, the visual communication profession in our country has developed rapidly and many colleges and universities have set up corresponding courses. At the same time, the demand for talents in the visual communication profession in society is increasing year by year. At present, Chinese visual communication professionals have reached more than one million, but the demand for talents is still very large.

With regard to talent demand and talent supply at the present stage, on the one hand, society seeks professionalism for professional visual communication professionals. On the other hand, talent supply in universities cannot fully meet the needs of the market in many aspects. This has caused, to a certain extent, a conflict between supply and demand of talents or an imbalance between supply and demand. The appearance of this kind of situation is caused by the malady of China's higher education system, that is, the scientific research and production have not formed an integrated system and the two are often separate from each other. On the other hand, there is a great relationship with the idea of professional construction in colleges and universities. There are still many problems in the visual communication profession in the construction of the curriculum system, or in the education and teaching methods, or the importance of theory and practice.

\section{Analysis of Problems in Visual Communication Major in Colleges and Universities}

As a first-line teacher engaged in related professional teaching, the writer has long been concerned with the theoretical development and practical results of professional construction. The author personally believes that in the context of quality education, there are still the following deficiencies in the overall construction of visual communication professionals in China's colleges and universities.

\subsection{Outdated teaching concept}

The visual communication specialty is a new discipline. This new phenomenon is not only 
reflected in the content of education and teaching, but also reflected in the education and teaching methods and reflected in the concept of education and teaching. We often say that theory is the forerunner of action. The concept of education and teaching has an important and irreplaceable guiding role in the overall development of education and teaching. However, the concept of education and teaching in many colleges and universities in our country is outdated, and the construction of disciplines is planned by empiricism or even taking it for granted. The specific performance in many colleges and universities is that they did not treat the practicality of the visual communication profession as an important attribute, blindly emphasizing theoretical indoctrination, less practical links in curriculum setting, and weak hands-on ability in students' comprehensive literacy. The curriculum system setting of some colleges obviously lags behind the social needs, and it is far from the actual requirements of teaching. At present, the visual communication majors of some colleges and universities still remain in the old visual skills education, and even the design of decorating. Although some colleges and universities have carried out some reforms in terms of curriculum setting and other aspects, they have tried very little. The reforms only touched a part of the teaching content and did not involve the creation of the entire curriculum system. There are corresponding designs for teaching practice activities in some colleges and universities, but they are mainly in the internship stage, far from the real integration of application, education and research requirements.

\subsection{Incomplete curriculum system}

At present, there is a big gap between the objectives of the visual communication professional curriculum system and the talent cultivation of many colleges and universities, and the curriculum system setting in many colleges and universities is not perfect. In the past few years, some colleges and universities have joined the digital art curriculum in the visual communication profession, but overall they are relatively isolated and do not constitute a complete system. Generally, one or two related courses are added. This piecemeal approach cannot highlight the true subject characteristics and academic characteristics of the visual communication profession. At the same time, colleges and universities did not fully consider the effective integration of visual communication related courses with other courses when setting up visual communication related courses. Quality education is a highly demanding talent training program and goal. It not only involves the isolated cultivation of students' professional knowledge in various disciplines, but also involves the cross-cutting of various disciplines. As far as the curriculum setting and construction of the visual communication professional are concerned, there is still a long way to go in the overall planning for the talent cultivation of quality education. At present, the choice of textbooks for visual communication professionals in China is single and backward, and many textbooks are limited to the basic knowledge level. Practical textbooks can be said to be rare, which greatly restricts the professional development of the profession.

\subsection{The disconnection between application and education}

The visual communication profession has very strong professional characteristics and practicality is a very representative one. However, at present, the curriculum of institutions of higher learning has largely ignored this important link. The curriculum planning and arrangement of college visual communication professional should fully consider the actual market and social needs, and should have a greater forward-looking. The establishment of personnel training and education and teaching in colleges and universities should follow the needs of social development, and in turn, grasp the context of professional development and establish a curriculum system that is compatible with social development. In the cultivation of talents, we should try our best to look to the future and target them with the goal of fostering professional and high-quality talents. However, the visual communication majors of universities in our country often adhere to traditional subjects in the curriculum construction and have not established a three-dimensional curriculum design approach. This has led to a large gap between students' professional knowledge and market operations and social needs. Therefore, many students find it hard to adapt after they have taken up 
jobs.

\section{Reflections on the Reform of Visual Communication Major Courses in Colleges and Universities}

As the main position for the training and output of talents in China, colleges and universities can be said to shoulder the historic responsibility of providing talent guarantees for socialist modernization and economic development. In the new historical period, colleges and universities should take the requirements of quality education as the driving force for the promotion of education and teaching, and develop students' knowledge, ability, and quality in an all-round and coordinated manner. The visual communication professional curriculum reform, as far as the author thinks, should focus on the following aspects.

\subsection{Change concepts and clear goals}

In the cultivation of visual communication professionals, we must first change our concepts. First of all, from the ideological point of view, there is a clear and scientific understanding of the development of this discipline. We must make clear what features this discipline has first, and how each of these features is strengthened and promoted in education and teaching. We must clarify the proportion of theoretical knowledge and practical knowledge that should be occupied in the discipline. The teaching of theoretical knowledge can achieve the desired teaching results through what kind of teaching materials and teaching methods. The practical links should be combined with the theoretical links to promote each other and improve each other. At the same time, we should abandon the old concept and fully recognize the important role that market plays in the training of talents and must guide the construction of disciplines in the spirit of serving local economic construction. Respect for knowledge, society and the market are not contradictory. We must look at the development of disciplines and curriculum systems with a development perspective. The purpose of cultivating applied talents is to take the initiative to connect with the local economy, and to actively connect with the frontiers of the discipline. Efforts are being made to cultivate talents with comprehensive development and creative thinking in the overall development of morality, intelligence, health, beauty and labor. School development should take quality as the guide, seek specialization construction and development, fully take talent demand as guidance and strive to achieve a seamless connection between industry and education. In terms of professional setup, we should base ourselves on the core direction of professional development and diversify and expand according to changes in the market. Students can choose their own development direction according to their own interests, hobbies and specialties. After completing the general education stage, students can linearly strengthen and improve their professional skills so that they can better adapt to future jobs.

\subsection{Update concept and continuously improve curriculum system}

The visual communication profession is not an isolated discipline. There are inextricable links between it and other disciplines. We should establish a visual communication professional curriculum structure with a multidisciplinary background. If we do not take a long-term perspective and are good at capturing changes in the market, we will only be able to phase it out by simply following the original textbooks and curriculum. The facts prove time and again that our current curriculum system can no longer meet the needs of the market and society. Therefore, in the construction of visual communication professional courses, we must have a sense of urgency, and treat such work with a sense of mission and responsibility that we should not wait for. First of all, we should fully consider the discipline development plan and carefully select the appropriate teaching materials. The selection of teaching materials should be handled by someone who is responsible for it. At the same time, subject teachers should be encouraged to participate fully in the selection of teaching materials. In terms of methods taught in the course, we must abandon the thinking of the past and make full use of popular teaching aids so that the amount of information in the classroom can be fully protected. In the theoretical and practical aspects, we should, according 
to the school's characteristics and guarantee capabilities, allow students to turn theoretical knowledge into practical skills and build their innovative ability on the basis of imitation and improvement. Based on the overall design framework of "big platform, small module", we will vigorously reorganize the curriculum system, focus on building a core curriculum system that meets industry characteristics and needs, and build modules based on the employment module and students' interests. At the same time, we should stage the practice of the students in the community and emphasize the integrated training courses such as basic sketching, graduation study, graduation practice and graduation design. From the beginning to the end, systematically optimize the practice link and increase the proportion of practical teaching in the entire teaching system.

\subsection{Deepen the promotion of professional talent team construction}

In the visual communication professional curriculum reform and professional construction, the construction of a professional talent team is the core and the key. We should adopt the measures for cultivating and introducing concurrent efforts to continuously strengthen the construction of related faculty and continuously improve the overall quality and overall standard of professional teachers. We must increase the training of teachers and encourage teachers to move toward a higher level of competence. We can select middle-aged and young teachers with a high level of professional abilities to go to fraternal colleges or abroad to conduct academic exchanges and encourage teachers to participate in the research. We should establish a scientific and effective talent introduction mechanism, vigorously introduce academic talents in the field, cultivate suitable talents and strive to forge an academic teacher team with strong research capabilities. While relying on professional teaching staff to carry out education and teaching reforms, it vigorously carried out education, teaching and research activities that are highly professional, interactive, and open. With teachers as the core, students are fully involved and their awareness of participation is enhanced. We must persist in promoting reform through openness, promoting development through openness, and constantly enhancing the influence and competitiveness of visual communication professionals.

\subsection{Fully implement the strategy of going global}

The implementation of the strategy of going global requires the joint efforts of both schools and enterprises. The visual communication profession is closely integrated with the market. In the construction and development of disciplines, we must fully emphasize the role of learning and establish a system of interlocking application, education, and research. Colleges and universities should pay attention to the cultivation of students' application ability and innovation ability, so that students can feel the importance of practice in the curriculum at the beginning of the discipline. In the recent period, many colleges and universities have carried out the construction of practical teaching bases and achieved remarkable results. The practical teaching base has played a very active role in promoting the strategy of going global. The construction of a practical teaching base must follow the two principles of operability and having a certain scale. Practical teaching bases are generally divided into two parts: on-campus and off-campus. The main part of the school is to hope that students will strengthen their mastery of theoretical knowledge on some virtual experimental platforms. The external part and the internal part of the school are completely different. The teacher no longer participates in the practice, but the cooperation between the company and the students completes the training work together. Colleges and universities should implement a variety of flexible production-learning-research cooperation practices according to local conditions. Colleges and universities should strengthen the construction of practical training bases, attach importance to school-enterprise cooperation, actively engage with companies in related fields, and encourage students to participate in social practice as much as possible. In the training, we learn about the latest developments in the industry, understand the shortcomings of students, understand the needs of enterprises, and constantly expand the school-enterprise cooperation approach from the depth and breadth to build a front-line teaching and research platform for the enterprise. We will strive to sign cooperative development agreements with 
companies, carry out technical research and application development work, and promote the coordinated development of subject specialization and industrial integration.

\subsection{Change the traditional evaluation system}

For many years, our subject evaluation system and schoolwork evaluation system have mainly focused on the theoretical part, which has led to our focus on performance and light practical ability. Therefore, we must make every effort to change the traditional evaluation system and incorporate the assessment of practical ability into the assessment of students' comprehensive quality.

\section{Conclusion}

The visual communication professional curriculum reform work is a urgent task. Only by establishing a complete curriculum system that meets the requirements of the market and social development can the visual communication professional develop into a wider and broader field in the future. In the context of quality education, we should fully recognize the deficiencies in the current professional and curriculum construction. Take students as the main body and take reform as the fundamental issue to find problems and solve them in a timely manner. Through the establishment of a basic and skills-based professional curriculum system, students will always occupy the forefront in the development of the future.

\section{References}

[1] Y. Liu. Research on Innovative Ideas of the Reform of Visual Communication Design Curriculum System [J]. Shandong Feed, 2013(21).

[2] C. C. Li and G. W. Li. Interpretation of Visual Communication Design Thinking in the New Century [J]. Packaging World, 2011(6).

[3] J. P. Zheng. An Analysis of Application-oriented Talent Cultivation of Visual Communication Design Specialty [J]. Journal of Shandong Arts and Crafts Institute, 2013(2).

[4] Q. Lei. Exploration and Reflection on Teaching Reform of Visual Communication Specialty in Applied Universities [J]. Art Education Research, 2017(13).

[5] H. Y. Zheng. Research on the Teaching Reform of Visual Communication under the Cultivation of Cultural and Creative Talents [J]. Science \& Technology Style, 2017(24).

[6] C. W. Qin and H. Ma. On the Visual Communication Professional Development in the Big Data Era [J]. Art Research, 2017(04).

[7] Z. H. Yu and Q. L. Yang. Teaching Reform and Breakthrough of Visual Communication Specialty Courses [J]. Journal of Heihe University, 2017(04). 